\title{
28 Facilitating sustainable dietary choices for positive nutritional and environmental outcomes
}

\author{
Maysoun A. Mustafa, Ayman Salama, \\ and Sayed Azam-Ali
}

\section{Introduction}

Egyptian mythology immortalises a deity - Suchos - with a mission to protect its subjects from natural threats, such as annual flooding of the river Nile which drastically affected food production and human populations (Naether 2019). Millenia later, despite humanity's mastery of shaping its environment, the struggle with balancing food production and environmental protection continues across the world.

Food systems fall within a nexus of agriculture, environment and health (Figure 28.1). To ensure access to sustainable food systems, the spheres of agriculture, environment and health need to operate in harmony with each other. The challenge we face is to manage the current needs of human populations against the capacity of our planet to provide these services for future generations (Foley et al. 2005). The role of Suchos as a protector of humanity is far from over, but now the power lies in the decisions that individuals make daily, and their capacities to make sustainable choices.

This chapter addresses the nexus between agriculture, environment and health. It introduces an artificial intelligence (AI) based platform - SuChos designed to facilitate sustainable dietary choices. Section A of the chapter provides an overview of barriers and opportunities for sustainability in food systems. Section B outlines the intervention that was developed by the team to deliver data-driven solutions to pressing global challenges. It outlines the AI-based platform that is designed to link communities to demonstrated solutions with measurable outcomes. Finally, section C describes the pathways towards adoption of the technology and its anticipated impact.

\section{Defining sustainable diets}

Sustainability is built on the delicate balance of three key elements: social inclusion, economic development and environmental sustainability (Mustafa et al. 2019). Within the context of food systems, this balance 


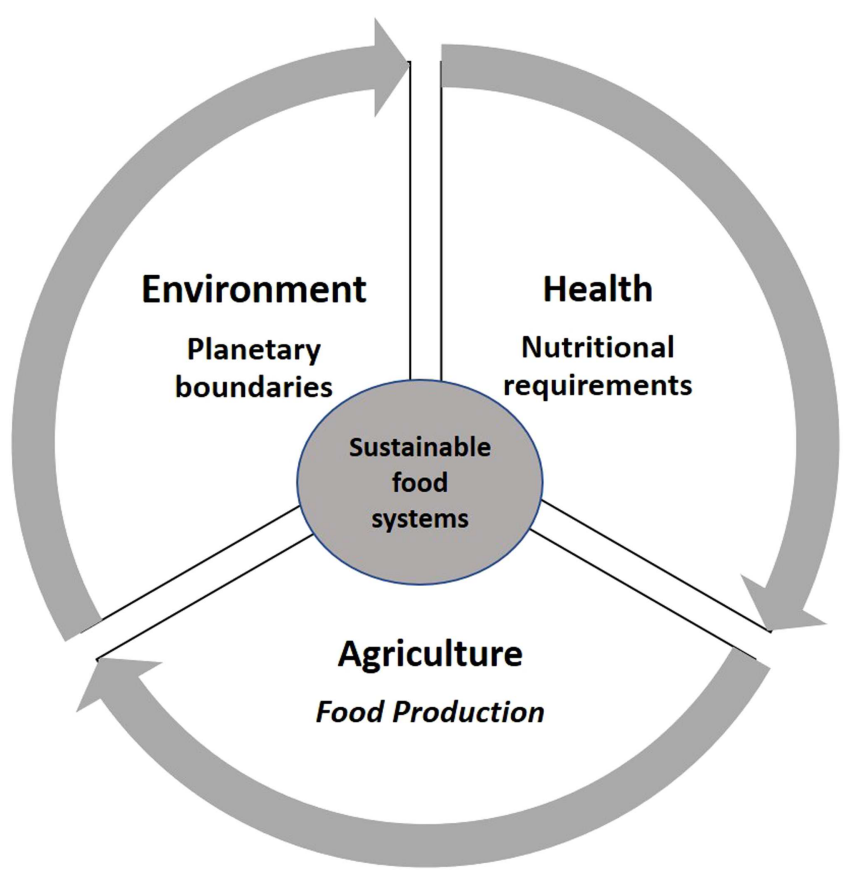

Figure 28.1 Nexus of agriculture, environment and health.

Source: adapted from Mabhaudhi et al. (2019).

presents as an attempt to ensure equitable access to healthy and safe food that is not at the expense of future generations. As we expect to see a $36 \%$ increase in global populations by 2050 (Tilman \& Clark 2014), food demands will naturally increase as well. The increase in food demands could have a drastic impact on depleting natural resources beyond planetary boundaries. The term 'planetary boundaries' implies the safe operating space within Earth's system based on nine dimensions: greenhouse gas emissions, nitrogen and phosphorus loading, ozone depletion, chemical pollution, freshwater use, ocean acidification, land-use change, aerosol loading and loss in biodiversity (Rockström et al. 2009).

More than ever, there is a need to define sustainable diets. Recently, the EAT Lancet report (Willet et al. 2019) was developed to establish a consensus on what constitutes a sustainable diet. In addition to the nutritional value of diets, the report also acknowledged the environmental impact of global foods and their production systems (Willet et al. 2019). Building on this consensus on nutritional value and environmental impact as important determinants of sustainable diets, this chapter includes societal demands as the third aspect to fulfil the requirements for a sustainable diet. 


\section{Nutritional demands}

Our modern food system is deeply challenged. For the third year in a row, hunger is on the rise (FSIN 2019). The proportion of the global population facing chronic food deprivation has increased from 804 million in 2016 to 821 million in 2017 (FSIN 2019). While an estimated 500 million people in Asia and 250 million in Africa face chronic undernourishment, an estimated 2 billion adults globally are overweight or obese and face threats of diet-related non-communicable diseases (FSIN 2019; Willet et al. 2019). Paradoxically, undernourishment and obesity can at times occur within the same country, community and even same household (NamZ 2018). Known as the 'nutritional paradox' or 'double burden of malnutrition', this has severe economic and health burdens as quantified using the comprehensive metric disability-adjusted life years (DALYs) (Godecke et al. 2018; NamZ 2018).

The consumption of nutrient-poor diets through inadequate quantities of fruit, vegetables and dietary fibres (Herforth et al. 2019) is now a major cause of non-communicable diseases. High-calorie nutrient-poor foods are increasingly found in urban settings and upper-middle and high-income countries (Baker \& Friel 2016). As unique and ethnic food habits are lost, consumption of processed and ready-to-eat food has increased the global consumption of free-sugars, fats and animal products (Herforth et al. 2019). While such consumers would have access to their minimum caloric requirements, alas they would be deficient in one or more essential micronutrient. As a result of these inadequacies in today's food system, an estimated 2 billion people globally suffer from 'hidden hunger' (Godecke et al. 2018).

To address the challenge of poor diets, we need to move from merely quantifying food security in terms of caloric intake, towards a more holistic discussion of nutritional security. This means addressing aspects of micronutrient deficiencies and related dietary deficiencies. Diets that comprise a diverse range of nutrient-dense foods are generally recommended as optimal for positive nutritional outcomes (Mustafa et al. 2019; Willet et al. 2019).

\section{Environmental demands}

A broader understanding of the environmental impacts of food production is emerging. While most people drink an average of two litres of water per day, per capita use of water is a staggering 3000 litres when the water used to produce their daily quota of food is considered (Economist 2008). Food production utilises approximately $70 \%$ of freshwater withdrawals as well as an estimated $85 \%$ of ground and surface water (FAO 2011). Thus, anticipated increases in food demand as populations grow and increase in affluence, will undeniably increase global pressures on our limited water resources (Rockström et al. 2009). Freshwater withdrawals are expected to increase by almost 55\% between 2000 and 2050 (Sokolow et al. 2019), while earlier 
estimates from the International Water Management Institute foresee an additional 2000 more cubic kilometres will be needed to feed a growing population by 2030 (Economist 2008). This is already a reality in a world that struggles with issues of water scarcity and climate challenges that exacerbate water accessibility.

Metrics to measure the water footprint of crops were developed by Mekonnen and Hoekstra (2014). They identified that most fruits and vegetables have lower water footprint and higher nutrient density than staple crops (Mekonnen \& Hoekstra 2014). Similarly, Nyathi and colleagues (2019) found traditional vegetables to possess higher nutritional yield and lower water footprint compared with non-native vegetables. Such indicators that account for both nutrition and environmental considerations are essential in our bid towards a more sustainable and resilient food system.

Evidence is increasingly becoming available on the carbon footprint of agricultural activities, thus allowing a better interpretation of the environmental costs of food production (Clune et al. 2016; Tilman \& Clark 2014). The Intergovernmental Panel on Climate Change (IPCC) special report on climate change and land describes a reality where food production is explicitly involved in the climate challenges that the world faces today and will likely be exacerbated (IPCC 2019). Emphasising the critical role of land use in combatting climate change, the report outlines that $23 \%$ of greenhouse gas emissions are derived from agriculture related activities (IPCC 2019). It outlines future scenarios with optimistic outcomes, which require changes in food systems towards healthier plant-based diets.

\section{Societal demands}

Access to information is key in influencing choices. Public awareness and education campaigns can impact dietary habits and food choices and effectively encourage informed decision-making by the public (Herforth et al. 2019). A strong interplay exists between individual decision-making and the accessibility of services. In addition, increasing digital literacy has seen the increase in development of and uptake of applications and the potential to use digital tools for sustainable food choices. Digitisation is profoundly changing our society, changing the way we work, produce, communicate or even how we consume. This is key in the integration of technologies for the development of SuChos.

A big question lies in the influence of food chains on consumer choices. Do big corporation or communities control markets? For example, in Asian markets, which are characterised by young populations and open markets, there is a clear increase in the presence of transnational food and beverage markets, specifically in ultra-processed food (Baker \& Friel 2016). More work is underway to explore the influence of price, accessibility, taste, convenience, nutrition on consumption and markets (Herforth \& Ahmed 2015), as well as empowering communities as drivers of changes in the food system (Nisbett et al. 2017). 


\section{Integration of technologies}

Our team developed a mobile-based application, SuChos, to facilitate sustainable dietary choices for individual consumers with potential to expand to communal actions. The platform integrates available data on sustainability aspects of food using state-of-the-art digital technologies. SuChos' backend computational systems (database, data engine, AI algorithm, data storage, data manager, visualisation) are hosted on the Google Cloud Platform. The mobile application is available on both Google and iOS store and integrates the following technologies.

\section{Global Food Database}

SuChos aims to build the largest food structured and unstructured database in the world. To date, the database at the core of SuChos contains data from five countries in three continents with more than one million food products and 70 million data points. SuChos integrates unstructured text data about food from 179 languages from the Wikipedia project. Data and text mining techniques are used to extract knowledge for semi or non-structured knowledge systems. One of SuChos' approaches is to integrate existing global efforts in collecting and curating food data, as well as incorporating food data that is not widely accessible.

Food behaviour is non-static and changes over time, occupying different meanings for different communities. SuChos recognises this need for agility and does not rely on conventional methods of applying rigid definitions and documentation of food. Thus, providing a constant flow of emerging knowledge around food culture and habits.

\section{Scientific tools to measure impact}

Based on the available data from the Global Food Database, nutritional values and environmental impact for each food item are calculated. A 'Health Index' is developed to visually assess and represent the nutritional value of specific foods using a 5 -star ranking system ( 1 being least positive, and 5 being most positive). This ranking is based on the Food Standards Agency Nutrient Profiling System (FSA-NPS) that assesses the content of nutrients that are associated with health outcomes (Julia \& Hercberg 2017). It is combined with the Nutrient Balance Score, a novel approach that evaluates the content of nutrients in composite meals and daily diets (Fern et al. 2015).

\section{Earth Index}

An 'Earth Index' is developed as an approximate measure of the greenhouse gas emissions of the food item consumed (Clune et al. 2016; Tilman \& Clark 2014), as well as the water footprint of the food item (Mekonnen 
\& Hoekstra 2014). Both water and carbon footprint are allotted equal weighting and represented using a 5-star ranking system that is comprehensible for a diverse audience.

\section{Intelligence Recommendation, Identification and Categorisation Engine (IRICE)}

At the core of SuChos is an Intelligence Recommendation, Identification and Categorisation Engine (IRICE); an AI engine designed to recommend the most suitable food to consumers. In a world of expanding knowledge, businesses have increasingly adopted recommendation engines to assist customers in the selection of content that is relevant and related to their habits. The nudge algorithm is a key component of IRICE, designed to recommend food choices that are better, both nutritionally and environmentally (Arno \& Thomas 2016). This allows consumers to choose foods that match their personal preferences and have a better environmental and nutritional impact.

As an example of the use of SuChos, we can imagine a customer walking into a restaurant or grocery shop and wishing to rapidly access the health and environmental information on a particular food item in a readable and visually appealing form. SuChos uses state-of-the-art technologies to provide such information within seconds. For this, the customer simply snaps a picture of the food product using the SuChos application. The image travels to the nearest cloud data centre of the SuChos network and is analysed using the best image classification (Russakovsky et al. 2015), using a deep neural network model to identify the food from millions of food products in less than a second (You et al. 2018). The IRICE engine compiles the relevant nutritional and environmental information and sends it back to the customer's phone in a visualisation form.

The SuChos recommendation engine is based on the most extensive food knowledge system in the world (Lops et al. 2011). Manual and automatic data collection are ongoing processes to mine and integrate all possible existing knowledge about food. The unstructured data is used for Natural Language Processing Machine Learning to compute a vector space of food knowledge. It is the base operational stage for the IRICE search and approximation engine for food identification and recommendation. Combining food knowledge with users' explicit preferences is used to build the turning-key knowledgebased recommendation engine that will serve SuChos users.

As the number of SuChos users and data generation expand, the IRICE recommendation engine will be ready to implement a 'Collaborative Filter' recommendation engine which enriches users' choices using their implicit and explicit interactions. The SuChos' approach is to implement a hybrid IRICE collaborative filter and content-based model to increase the accuracy of the SuChos recommendation engine to provide the best user experience in their food journey (He et al. 2017). 


\section{Pathway to sustainable impact}

Globally, communities increasingly wish to celebrate and embrace healthier and more sustainable foods. This is particularly evident in the growing number of food-based dietary guidelines that are adopted by national and international bodies (Herforth et al. 2019). Such guidelines identify links between dietary habits and health outcomes, translating existing evidence on food and health into recommendations to influence policies and consumer behaviour. SuChos is designed as a platform building on an expanding database of global foods and eating habits to actively advise consumers on their dietary habits.

SuChos integrates a global food database comprising of ingredients and photos with scientific tools to measure nutritional and environmental data, along with stories from communities (Figure 28.2). Using AI-assisted solutions, this platform aims to support communities in making informed choices on the food they consume and plan for balanced and healthy diets. It aims to build a culture of transparency on the food that is produced and marketed globally by engaging commercial food producers in the process and encouraging communities to measure the impact of the food they consume using user-friendly scientific tools. Badges and digital prizes are designed to match rewards to global targets for the United Nations Sustainable Development Goals (SDG), such as SDG2 (Zero Hunger and Improved Nutrition) and SDG 6 (Clean Water and Sanitation).

Collectively, by combining the experiences, stories and recipes of the communities on the SuChos platform through machine learning-driven technologies, SuChos aspires towards encouraging communities (producers and consumers) to align their lifestyles with the SDGs and have a positive impact on their health and environment.

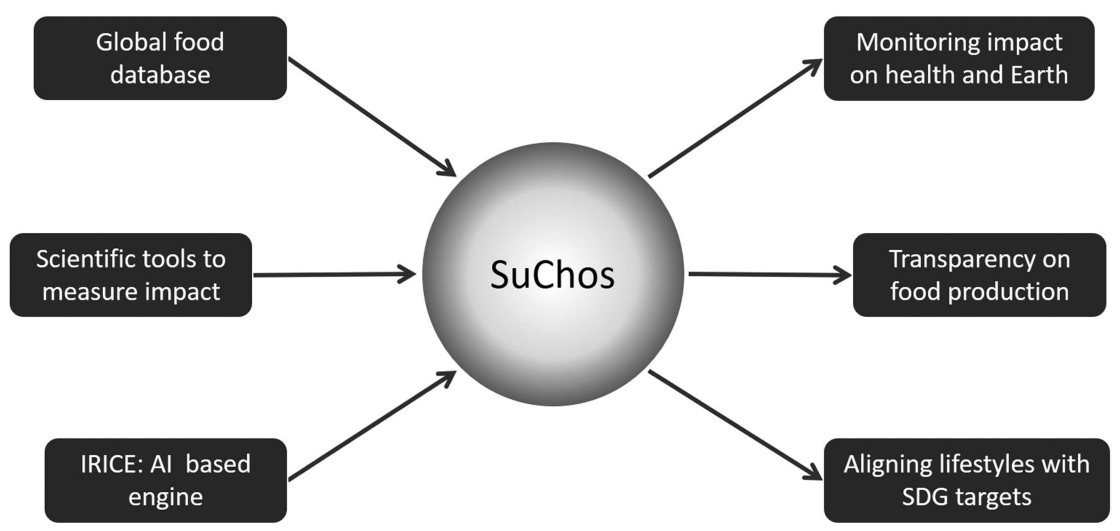

Figure 28.2 The pathway to impact for the developed platform SuChos. 


\section{Recommendations}

Such a breadth and quantity of publicly available data is now available to support decisions globally on sustainable food systems. However, such data are not currently integrated into an easily accessible format for consumers to make informed choices to guide their own behaviour. The availability of indicators and state of art technologies are integrated on the SuChos platform to calculate and monitor nutritional and environmental considerations of our food systems. We are not aware of any comparable application that can rapidly make such information available to individuals to make their own decisions on how to support sustainable and nutritious food systems that respect our planetary boundaries.

\section{Abbreviations}

$\begin{array}{ll}\text { AI } & \text { artificial intelligence } \\ \text { DALYs } & \text { disability adjusted life years } \\ \text { FSA-NPS } & \text { Food Standards Agency Nutrient Profiling System } \\ \text { IPCC } & \text { Intergovernmental Panel on Climate Change } \\ \text { IRICE } & \begin{array}{l}\text { Intelligence Recommendation, Identification and Categorisation } \\ \text { Engine }\end{array} \\ \text { SDGs } & \text { Sustainable Development Goals }\end{array}$

\section{References}

Arno, A., and Thomas, S. (2016). The efficacy of nudge theory strategies in influencing adult dietary behaviour: a systematic review and meta-analysis. BMC Public Health, $16,676$.

Baker, P., and Friel, S. (2016). Food systems transformations, ultra-processed food markets and the nutrition transition in Asia. Global Health, 12, 80.

Clune, S., Crossin, E., and Verghese, K. (2016). Systematic review of greenhouse gas emissions for different fresh food categories. Journal of Cleaner Production, 140, 766-783.

Economist. 2008. Water for farming: running dry. The Economist. Retrieved from www. economist.com/international/2008/09/18/running-dry.

FAO. (2011). The state of the world's land and water resources for food and agriculture-managing systems at risk. Retrieved from www.fao.org/docrep/017/ i1688e/i1688e.pdf.

Fern, E. B., Watzke, H., Barclay, D. V., Roulin, A., and Drewnowski, A. (2015). The nutrient balance concept: a new quality metric for composite meals and diets. PLOS One, 10(7), e0130491.

Foley, J. A., DeFries, R., Asner, G. P., Barford, C., Bonan, G., Carpenter, C. R. et al., (2005). Global consequences of land use. Science, 22(309) (5734), 570-574.

Forouzanfar, M. H., Alexander, L., Anderson, H. R., Bachman, B. F., Biryukov, S., Brauer, M. et al., (2015). Global, regional and national comparative risk assessment of 79 behavioural, environmental and occupational and metabolic risks or clusters of risks in 188 countries, 1990-2013: a systematic analysis for the Global Burden of Disease Study 2013. Lancet, 386, 2287-2323. 
FSIN. (2019). Global report on food crises. Retrieved from www.fsinplatform.org/sites/ default/files/resources/files/GRFC_2019-Full_Report.pdf.

Godecke, T., Stein, A. J., and Qaim, M. (2018). The global burden of chronic and hidden hunger: trends and determinants. Global Food Security, 17, 21-29.

He, X., Liao, L., Zhang, H., Nie, L., Hu, X., and Chua, T. S. (2017). Neural collaborative filtering. In Proceedings of the 26th International Conference on World Wide Web (pp. 173-182). International World Wide Web Conferences Steering Committee.

Herforth, A., Arimond, M., Alvarez-Sanchez, C., Coates, J., Christianson, K., and Muehlhoff, E. (2019). A global review of food-based dietary guidelines. Advances in Nutrition, 10(4), 590-605.

Herforth, A., and Ahmed, S. (2015). The food environment, its effects on dietary consumption, and potential for measurement within agriculture-nutrition interventions. Food Security, 7, 505-520.

IPCC. (2019). Climate change and land: an IPCC special report on climate change, desertification, land degradation, sustainable land management, food security, and greenhouse gas fluxes in terrestrial ecosystems. IPCC, Geneva.

Julia, C., and Hercberg, S. (2017). Nutri-Score: evidence of the effectiveness of the French front-of-pack nutrition label. Ernahrungs Umschau, 64, 181-187.

Lops, P., De Gemmis, M., and Semeraro, G. (2011). Content-based recommender systems: state of the art and trends. In Recommender systems handbook (pp. 73-105). Springer, Boston, MA.

Mabhaudhi, T., Chibarabada, T. P., Chimonyo, V. G. P., Murugani, V. G., Pereira, L. M., Sobratee, N., Govender, L., Slotow, R. and Modi, A. T. (2019). Mainstreaming indigenous crops into food systems: a South African perspective. Sustainability, 11, 172.

Mekonnen, M. M., and Hoekstra, A. Y. (2014). Water footprint benchmarks for crop production: a first global assessment. Ecological Indicators, 46, 214-223.

Mustafa, M. A., Mateva, K., and Massawe, F. (2019). Sustainable crop production for environmental and human health - the future of agriculture. Annual Plant Reviews, 2, 1117-1140.

Naether, F. (2019). New deities and new habits. a companion to Greco-Roman and Late Antique Egypt, 439-447.

NamZ. (2018). Together we can tackle the nutritional paradox. Retrieved from http:// nutritionalparadox.com.

Nisbett, N., van den Bold, M., Gillespie, S., Menon, P., Davis, P., Roopnaraine, T. et al., (2017). Community-level perceptions of drivers of change in nutrition: evidence from South Asia and sub-Saharan Africa. Global Food Security, 13, 74-82.

Nyathi, M. K., Mabhaudhi, T., Halsema, G. E., van Annandale, J. G., and Struik, P. C. (2019). Benchmarking nutritional water productivity of twenty vegetables - a review. Agricultural Water Management, 221, 248-259.

Rockström, J., W. Steffen, K. Noone, A. Persson, F. S. Chapin, III, E. Lambin, T. M. Lenton, M. Scheffer, C. Folke, H. Schellnhuber, B. Nykvist, C. A. De Wit, T. Hughes, S. van der Leeuw, H. Rodhe, S. Sorlin, P. K. Snyder, R. Costanza, U. Svedin, M. Falkenmark, L. Karlberg, R. W. Corell, V. J. Fabry, J. Hansen, B. Walker, D. Liverman, K. Richardson, P. Crutzen, and J. Foley. (2009). Planetary boundaries: exploring the safe operating space for humanity. Ecology and Society, 14, 32.

Russakovsky, O., Deng, J., Su, H., Krause, J., Satheesh, S., Ma, S. et al., (2015). Imagenet large scale visual recognition challenge. International Journal of Computer Vision, 115, 211-252. 


\section{Maysoun A. Mustafa et al.}

Sokolow, J., Kennedy, G., and Attwood, S. (2019). Managing Crop tradeoffs: A methodology for comparing the water footprint and nutrient density of crops for food system sustainability. Journal of Cleaner Production, 225, 913-927.

Tilman, D., and Clarke, M. (2014). Global diets link environmental sustainability and human health. Nature, 515, 518-522.

Willet, W., Rockström, J., Loken, B., Springmann, M., Lang, T., Vermeulen, S. et al., (2019). Commission food in the Anthropocene: the EAT-Lancet Commission on Healthy Diets from Sustainable Food Systems. The Lancet, 393, 10170, 447-492.

You, Y., Zhang, Z., Hsieh, C. J., Demmel, J., and Keutzer, K. (2018). Imagenet training in minutes. In Proceedings of the 47th International Conference on Parallel Processing (p. 1). ACM. 